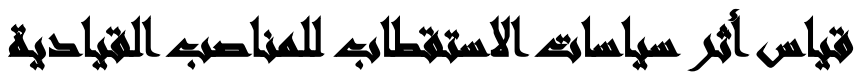

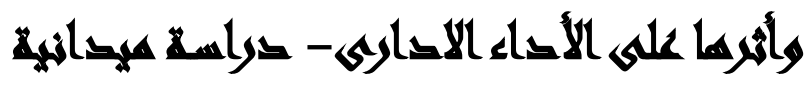

[17]

$$
\text { محمد عبد العزيز عبد العزيز صيام }
$$

المعهذ العالي للعلوم الإدارية والحاسابات بالعبور

\begin{abstract}
الممتخلم
استهدفت الدراسة قياس أثز سياسات الاستقطاب للمناصب القيادية وأثزها على الأداء

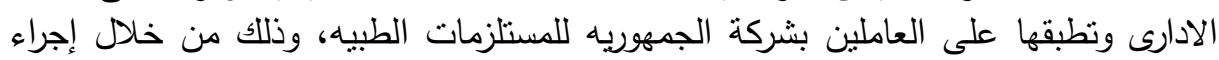

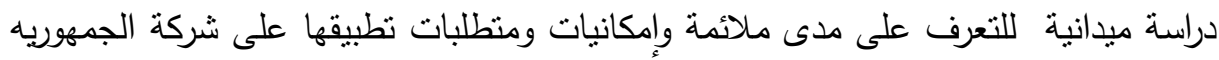
للمستلزمات الطبيه المقترحة لهذا للتطبيق.

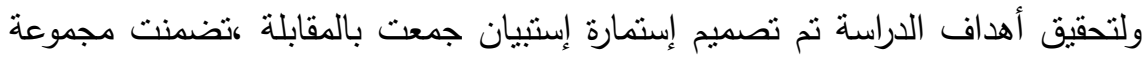

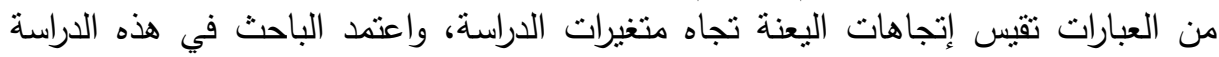

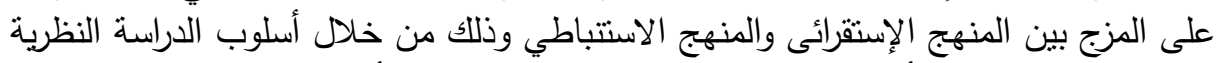

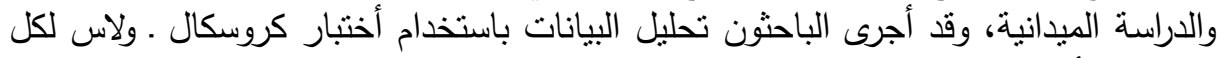

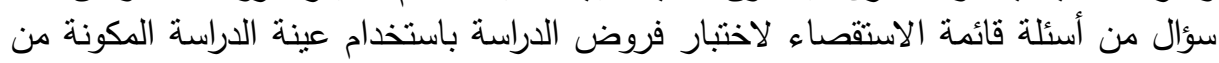

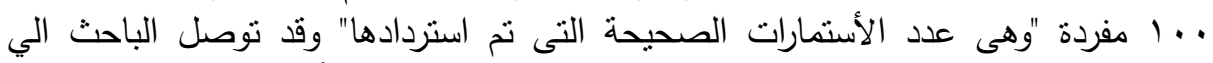

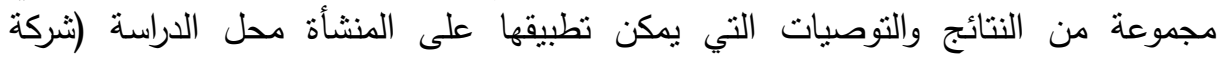
الجمهوريه للمستلزمات الطبيه).

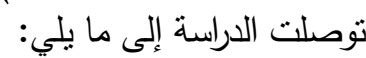

1- الاهتمام بوضع سياسات وإجراءات من شأنهات إنها ممارسة وتعزيز العمل على الاستقطاب.

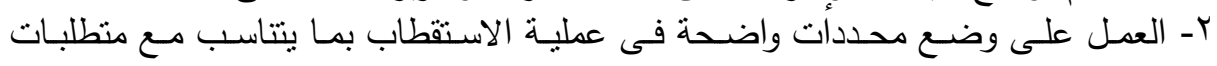
الوظيفة الثاغرة.

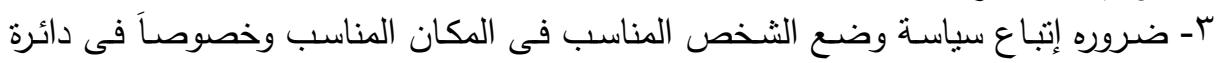
الاستقطاب للمناصب الإدارية.
\end{abstract}




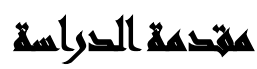

يعتبر المورد البشرى مورداً مهما وأصلاً من الأصول التى تمتلكها المنظمات ،فإنسان

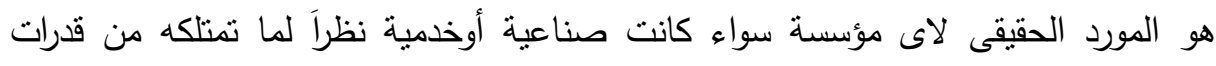

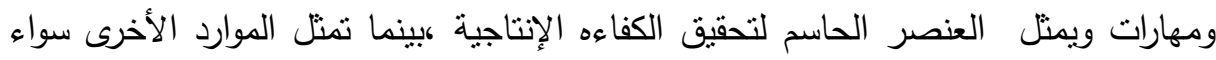

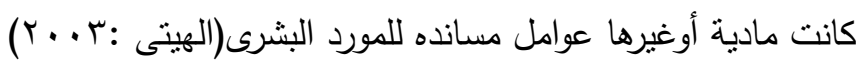

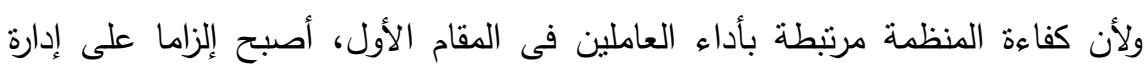
الموارد البشرية الأهتمام بشكل كبير بالسياسات العامة للأفراد إبتداء من الاستقطاب ومروراً

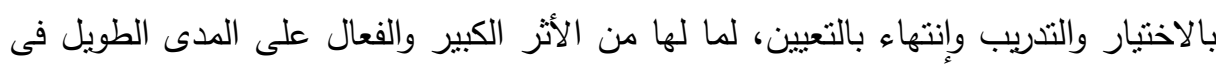

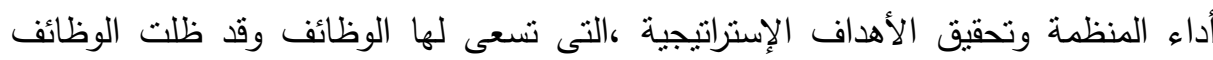

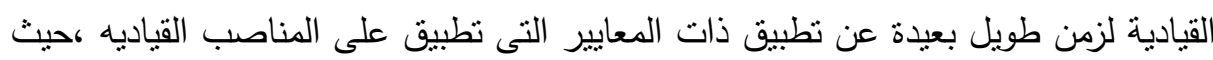

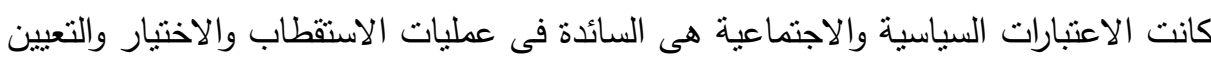

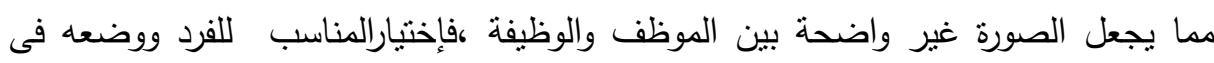
مكان وظيفى بلزم المنظمة الاحتفاظ به مهما كانت نوعية المهارات والقدرات والمعارف التى

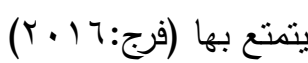
ومن خلال ما سبق :يمكن القول أن الاستقطاب الفعال يؤثر على فاعلية الأداء الإدارى

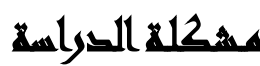

يشهد العصر الحالى تحولات وتغيرات جذرية واقتصادية فى جميع مجالات الحياة،نتجة

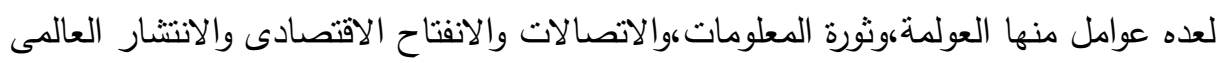

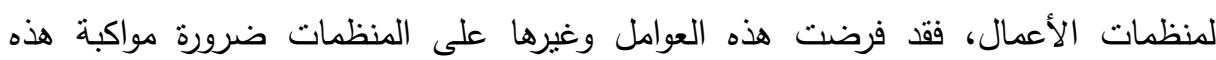
التغيرات وإنباع طرق حديثة فى التقكير وانتهاج طرق مبتكرة فى العمل الإدارى ،لكى تبقى لها لهاء موضع قائم بين هذه المنظمات.

ولان أختبار العنصر البشرى المؤهل والمدرب يعتبر من العوامل الرئيسية لنجاح أى منظمة. 
ويرى (ماهر:؟؟ . ب) أن عملية البحث عن الأفراد المؤهلين وجذبهم لشغل الوظائف

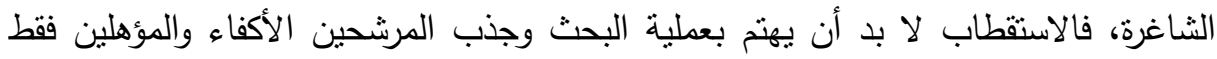
للوظيفة،ويصعب تحقيق النجاح فى الاستقطاب إذا كانت الوظائف المراد شغلها تثميز بالغموض فى توصيفها وتعرفها، فلا بد أن تعرف وتوصف من حيث متطلباتها بطريقة دقيقة

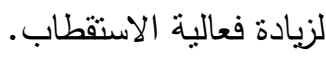

وتعتبر سياسات الاستقطاب للمديرين واختيارهم وتعينهم إحدى العمليات الرئيسية التى التى

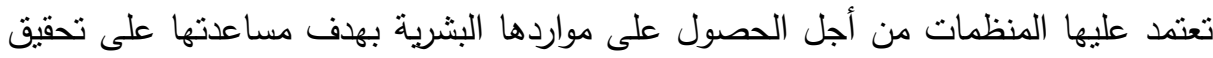

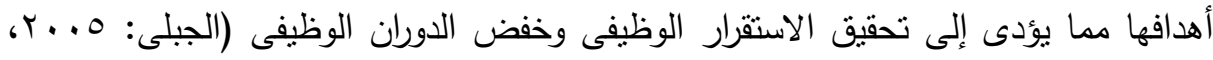

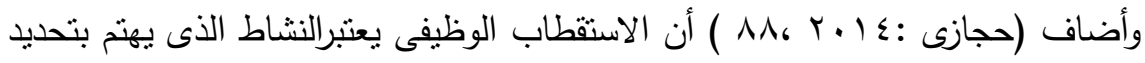

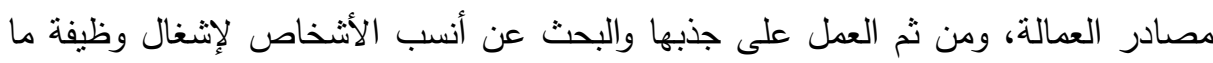

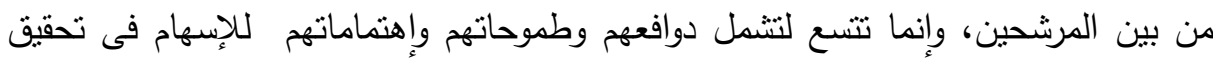
أهداف المنظمة .وأكد أن الاستقطاب الوظيفى هو نشاط ديناميكى فى المنظمة كونه المصدر

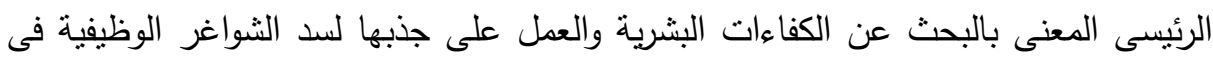
المنظمة وذللك بالعدد والنوعية المطلوبة المرغوبة فى الوقت المناسب، بجانب إنها وظيفة تعنى

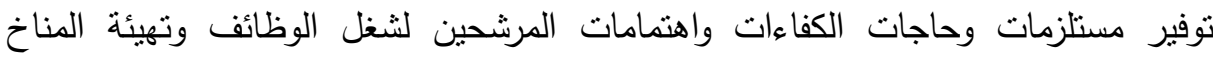

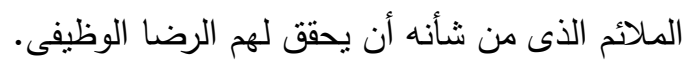
وأشار ( Daripaly, P: 2005 ) أن الاستقطاب الجيد يؤدى إلى تحسين النى الأداء الإدارى للمنظمة ككل. والأداء الإدارى له أهية بالغة وذللك لارتباطة بعدة عوامل منها التتظيم الإدارى والهيكل التنظيمى ودراسة الإجراءات وتتسيط تتمثل مشكلة الدراسة فى محاولة التعرف على كيفية الإدارة الفاعلة وكيفية تقويم الأداء

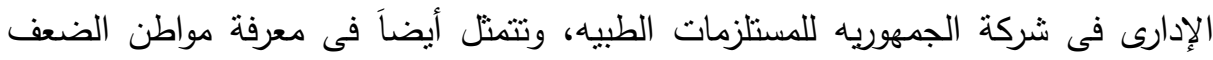


والقوة وأكتشاف الانحرافات التى تطرأ على الأداء من خلال التغيرات والمؤشرات المحيطة

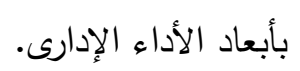

تتمنل مشكلة الدراسة فى تحديد درجة التزام (شركة الجمهوريه للمستلزمات الطبيه) بمعايير الاستقطاب والاختبار والتعيين التى تنتخدمها الثركة، ومدى ثأثثير ذلك على تحقيق تلثئ الأداء الادارى لللقيادات الإدارية. سؤال الاراسة: قياس أثز سياسات الاستقطاب للمناصب القيادية وأثزها على الأداء الادارى الإد

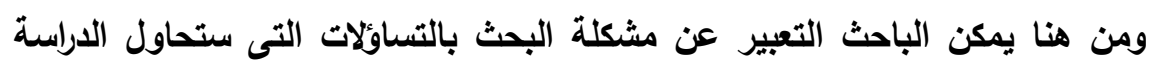

الإجابة عليها. وينبيثق من هذا التسأل الرئيسى التساؤلات الفرعية التالية:

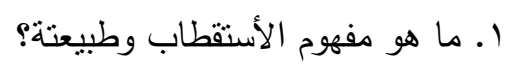

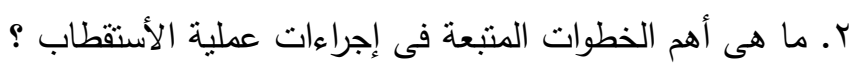

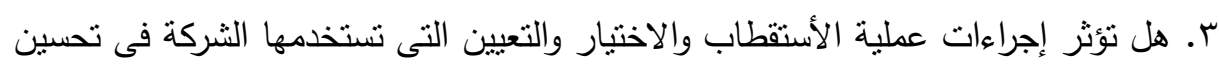
الكفاءة الإدارية ؟ بؤر إجراء ء. هل الاستقطاب الفعال للقيادات يؤدى إلى خفض معدل دوران العاملين بالشركة محل الدراسة؟

\section{أهسا هـ التوراسة}

يتمثل الهدف الرئيسى للاراسـة فى قياس أثر سياسات الاستقطاب للمناصب القيادية على الأداء الادارى على شركة ( الجمهوريه للمستلزمات الطبيه ) ويتم تحقيق هذا الهدف من خلال مجموعة من الأهداف الفرعية التالية: 1. القاء الضوء على مفهوم سياسات الاستقطاب وعناصرها وفوائدها وأهم معوقات تطبيقها فى الأى

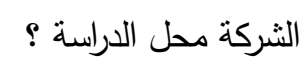
r. .التعرف على مدى تأثير سياسات الاستقطاب المتبعة فى الثركة محل الدراسة.

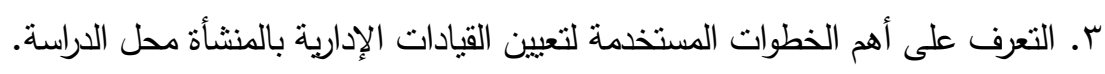


ع - دراسة الاختلاف بين أراء عينة الدراسة حول متغيرات الدراسة تعزى للمتغيرات الديموغرافية

$$
\text { المتمنتة فى (النوع- السن-المستوى الوظيفى) }
$$

\section{أهمري القواسمة}

1- أن موضـوعات الموارد البشـرية بشكل عام تولى أهتمامـاً خاصـا بتطوير أنشطة المؤسسـات

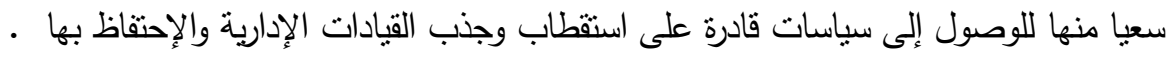
ץ-على المستوى العلمى يأتى التعرف على استقطاب القيادات للمناصب الإداريـة وأهدافها من وجه نظر أفراد عينة الدراسة ليساهم فى تحسين أداء العمل الإدارى.

\section{السراسايت الساريخ}

قام الباحث بتتاول أهم الدراسات السابقة العربية والأجنبية المتعلقة بمشكلة الدراسة فى ضوء ما توافر له وذللك على النحو التالى: الدراسات السابقة العربية والأجنبية وتتاول الباحث فيما يلى أهم هذه الدراسات طبقاً للنسلسل التاربخى.

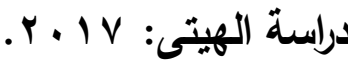

هدفت الدراسة إلى: التعرف على واقع الوظائف المهنية فى الجهاز الحكومى الأردنى والمتمنلة بمنصب الأمن العام والمدير العام والمتغيرات الوظيفية المرتبطة بها، وعلاقة ذلك بالنتائج المتحققة

\section{توصلت نتائج الاسة إلى ما يلى:}

1- أن هناك علاقات ذات دلالة إحصائية ولكنها منخفضة بشكل عام بين أبعاد الدراسة. ץ-أن هناك علاقات ذات دلالة إحصائية بين المتغير المستقل استقطاب وظائف الإدارة العليا وبعد نتائج شغل المنصب. r- أن هناك علاقات ذات دلالة إحصائية بين المتغير المستقل استقطاب وظائف الإدارة العليا وبعد الأداء فى المنصب. 


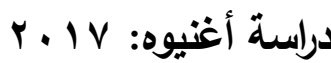

هدفت الدراسـة إلىى: القاء الضوء على مفهوم وسياسـات الاستقطاب وعناصـرها وفوائدها وأهم معوقات تطبيقها، والتعرف على مدى نأثثر سياسات الاستقطاب المتبعة فى الثركة العامة للكهرباء فى ليبيا على فاعلية أداء العاملين فى المراكز القيادية.

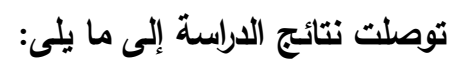

1-وجود أثر ذو دلالـة إحصـائية لسياسـات الاستقطاب متصنلة في البعدين (التخطيط للمنصب، والاستقطاب الداخلى ) على نتائج شغل المنصب. r-وجود أثز ذو دلالة إحصائية لسياسات الاستقطاب على فاعلية الأداء الإدارى ككل.

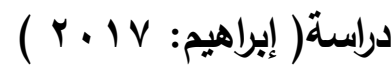
هدفت الدراسـة إلى: التعرف على أثر فوائد الاسنقطاب للمنظمة (الكفاءة - الفاعلية - العدالة)

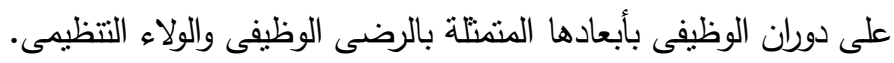

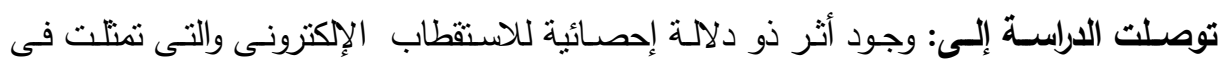
(الكفاءة - الفاعلية - العدالة) على معدل الدوران الوظيفى. تودلئ. (Y. IV: Carolina دراسة (1) هدفت الدراسة إلى: معرفة طريقة تتفيذ إدارة الموارد البثرية وإستخدام التكنولوجيا الحديثة فى عملية الاستقطاب والتوظيف. توصلت الدراسة: إلى أن الثركة التى تستخدم النوظيف الإككترونى بدلا من الطريقة التقليدية

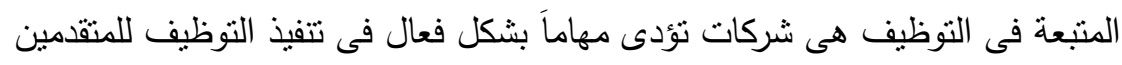




\section{دراسة (Y • V V:Sheila)}

هافت الاراسة إلى التعرف على تطبيقات وممارسات عملية الاستقطاب فى المؤسسات، وإلى

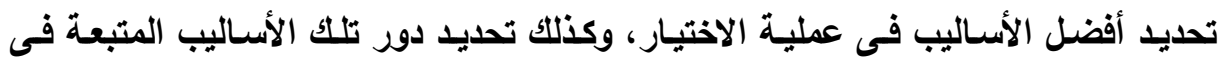

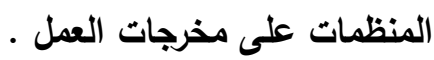
توصلت الدراسة: إلى أن أكثر الاساليب تطبيقاً فى عملية أستقطاب الموظفين هى الإعلانات بمختلف أنواعها المسموعة والمرئية.

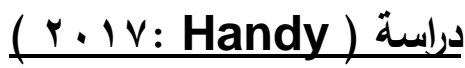
هـدت الاراســة: إلى تاكيد على أهميـة أسلوب المقابلـة الثخصية فى إستقطاب واختيـار المناصب الإدارية الملائمة للعمل فى المنظمات فى بنسفانيا بالوليات المتحدة الامريكية.

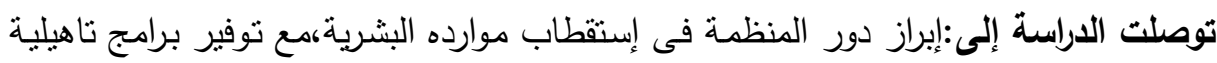
كفيلة بتحقيق أهداف المنظمة ومنها تحقيق النتافسية والريادة لهذه المنظمات.

\section{هـروض التراسلة}

من أجل تفسير إثنكالية الدراسة ومحاولة الإجابة عن الأسئلة المطروحة يمكن صياغة

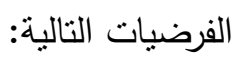
الفرض الرئيسى الأولي: توجد علاقة ذات دلالة إحصائية بين سياسات الاستقطاب على نتائج شغل المناصب الإدارية. الفرض الرئيسى الثانى: نوجد علاقة ذات دلالة إحصائية بين سياسات الاستقطاب ككل على الإنى

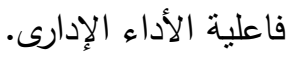




\section{الإسطار اللنظليها}

تشمل الدراسة على عدد من المفاهيم التي لابد من توضيحها وتحديد المقصود منها وهي

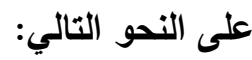

1- يعرف الإستقطاب على إنه:عملية اكتشاف مرشحين محتملين للوظائف الثشاغرة الحالية أو

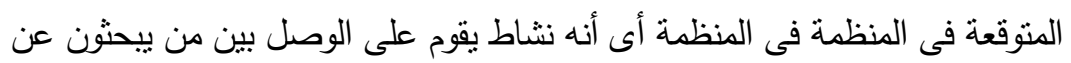

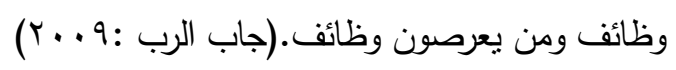

r- كما يعرف الاستقطاب: بأنه تلك المراحل أو العمليات المختلفة للبحث عن المرشحين

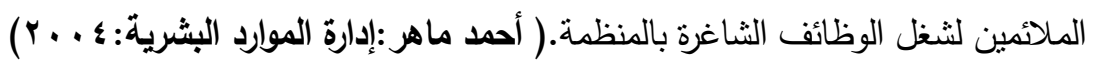

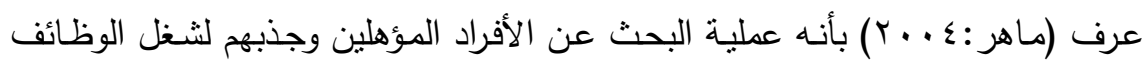

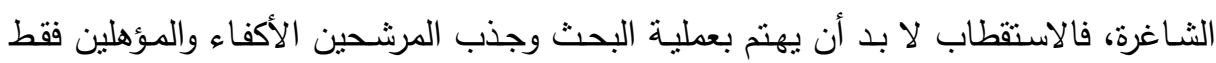

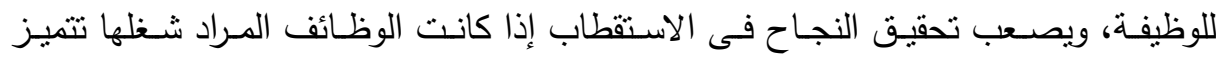
بالغموض فى توصيفها وتعرفها، فلا بد أن تعرف وتوصف من حيث منطلباتها بطريقة دقيقة

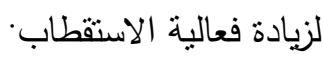

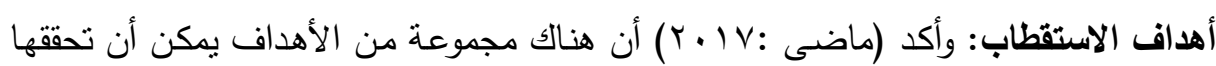
علية الاستقطاب ومنها ما يلى: 1-تحديد الأفراد الذين يمكن الحصول عليهح لشغل الوظائف الثاغرة.

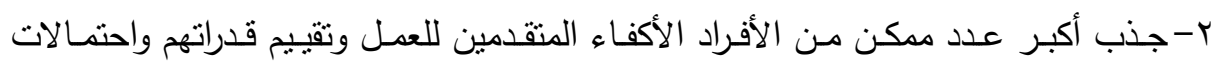
نجاحهم في الأعمال بشرط تحقيق التوازن بين العائد والتكلفة.

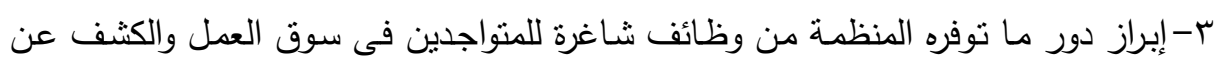

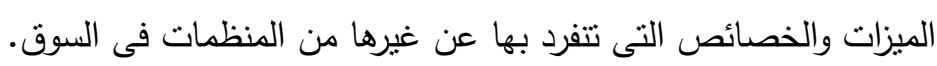
ع-كسب ثقة الأفراد الساعين وراء الوظائف الثـاغرة سواء تم توظيفهم أم لا للاستفادة منهم مستقبلاً كموظفين واعدين تحت الطلب. 
مفهوم الاختيـار والتعيين: تعريف (شيحة: . . . ب)عرف الاختيار والتعيين على أنه عملية البحث والمفاضـلة بـين مجموعـة مـن الأفراد تتـوفر فيهم الخصـائص والصـفات والمهـارات المطلوبة والتى تتلائم مع متطلبات التوظيف لاختبار الأكثر فاعلية فى العمل والحصول علئ عليهم بالعدد المطلوب لشغل الوظائف الثاغرة، على أن يكون ذلك مقروناً برضاهم ورغباتهم، وبذللك

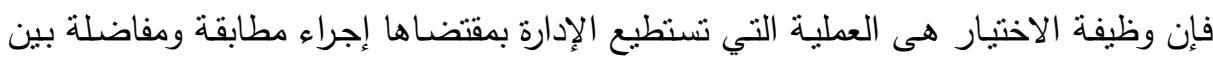
مواصفات الأفراد الراغبين فى العمل ومنطلبات العمل، وأن عملية التميز والمفاضلة بين الأفراد المتقدمين للعمل تتن بالاختيار أفضلهم من حيث درجة صـلاحيتهم لأداء ذلك العمل بنجاح وفاعلية.

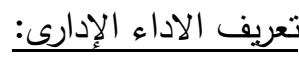
مفهوم الأداء: يعنى الإنجازالناجم عن ترجمة المعارف النظرية إلى مهارية النى مهات من خلال الممارسة العطلية والتطبيقية لهذه النظريات وبواسطة الخبرات المتراكمة والمكتسبة فى مجال العمل تردية

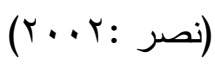

الأداء الإدارى يتعلق بما يقوم به موظف أو مدير من أعمال وأنشطة مرنبطة بوظيفة معينة

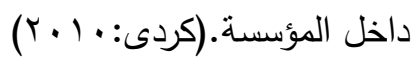

\section{إجبراءايت الكراسمة}

الاراسة الميدانية (المنهج التحليلي): اعتمد الباحث في إجراء الدراسة الميدانية على قائمــة الاستقصـاء والتـي تم توزيعها على عينــة مـن المـديرين والعـاملين بشـركة الجمهوريـة

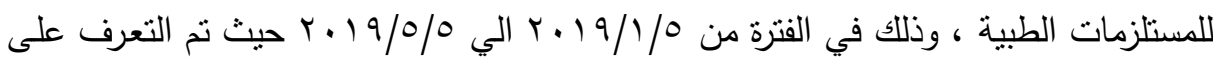

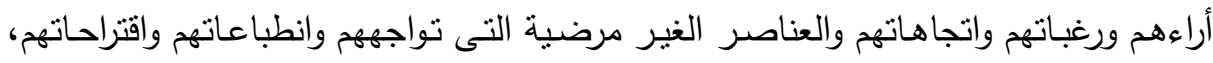
وقد تم استخدام الأساليب الإحصائية في تحليل البيانات والمعطيات التي تم جمعها. 
وقد توصلت الدراسة إلى وجود فجوة بحثية لم تغطيها العديد من الدراسات السابقة، ومن ثم أهتمت الدراسة بإجراء دراسة إستكثافية في المجال التطبيقي، ثم تم استعراض نتائج الدراسة

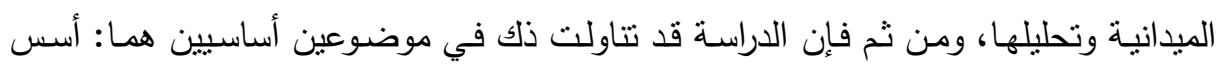

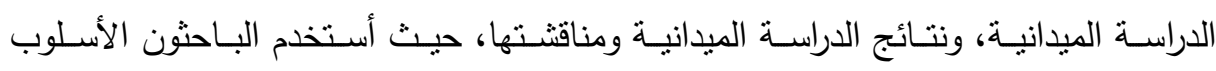

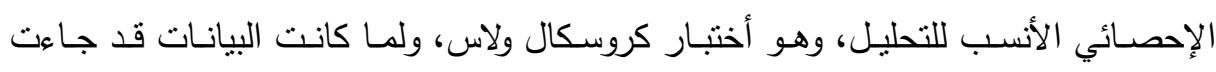

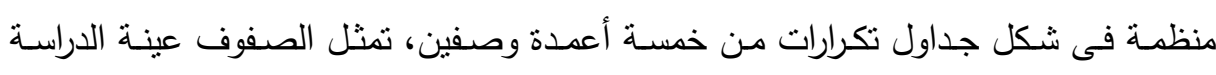
(المديرين بشركة الجمهورية للمستلزمات الطبية ) وتمثل الأعمدة استجابات الأفراد على أسئلة الاستقصاء والتى ثم ترتيبها نتازلياً من موافق تماماً إلى لا أوافق مطلقاً.

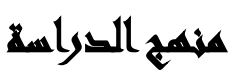

فى ضوء طبيعة المشكلة وهدف وأهية الدراسة أعتمد الباحث على منهجين أساسيين فى

أعداد الدراسة هما:

1-المنهج الوصفي التحليلي: حيث قام الباحثتون بالإطلاع وإستقراءالدراسات العلمية التى

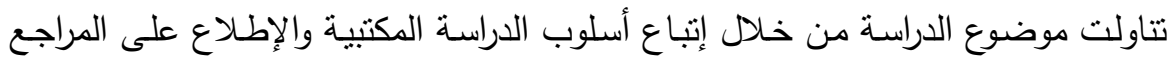

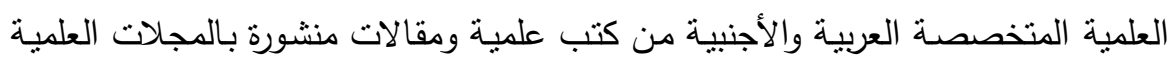

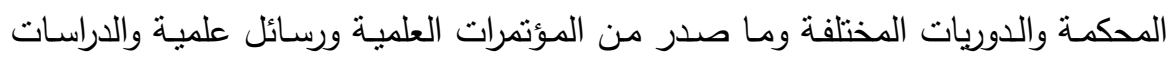

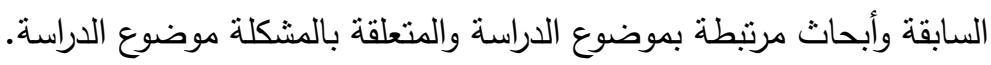

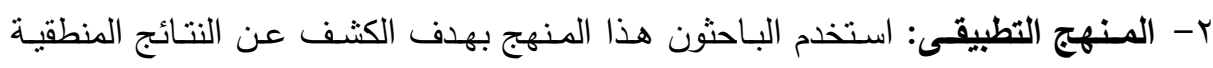
المترتبـة على إختبار الفروض الأساسية للاراسـة، وذلك من خـلال القيام بدراسـة ميدانيـة

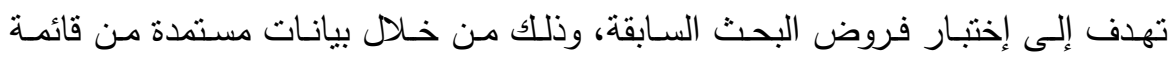
إستقصاء لإسنطلاع الرأى تم توزيعها على المديرين بشركة الجمهورية للمستلزمات الطبية. 


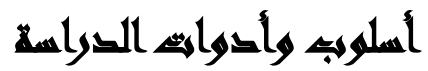

أ- مجتمع الدراسة والتعينة: يمكن توضيح كلاً من مجتمع وعينة الدراسة كما يلي:

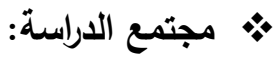

يتمثل مجتمع الدراسة من المديرين بشركة الجمهورية للمستلزمات الطبية

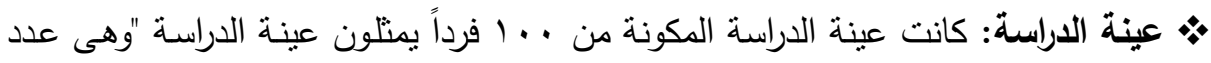

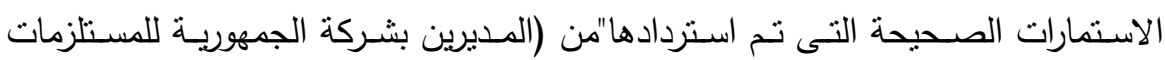

$$
\text { الطبية ) }
$$

ونظراً لطبيعة البيانات التى تتسم بندرة الاستجابة على بعض فئات الاستجابة خاصة فئة

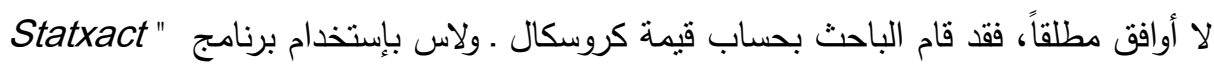

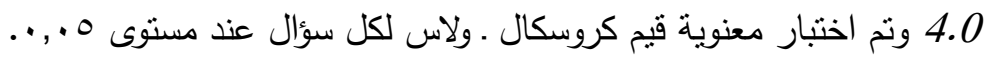

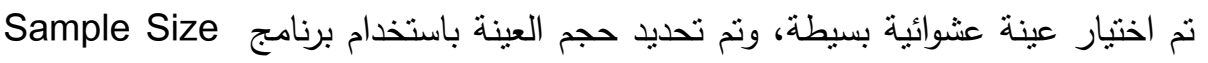
Calculator

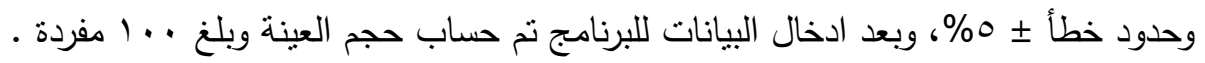
ب- قياس متغيرات الدراسة: في ضوء الدراسات السابقة التي إطلع عليها الباحثون، فقد اعتمد البـاحثون في قيـاس المتغير المستقل (سياسـات الاستقطاب للمناصـب القياديـة )

$$
\text { والمتغير التابع (الأداء الإدارى). }
$$

نم تطبيق المقياس فى صورته المبئية على عينة استطلاعية Pilot study قوامها (0. مفردة من العاملين فى المعاهد محل الدراسة وذللك لاختبار صدق المقياس المستخدم فى الدراسة، وقد تم استخدام معامل كرونباخ الفاC Cronbach's Alpha بهدف قياس معامل الثبات (درجة الاعتمادية)، والصدق الذاتي الذى يمثل (الجذر التربيعي لمعامل الثبات) وذلك على مستوى جميع المتغيرات الخاصة بأبعاد " أثر الاحترلق لوظيفي على رأس المال الفكري) 
جدول رقم (1): معاملات الصدق والثبات لإجمالي أبعاد " سياسات الاستقطاب للمناصب

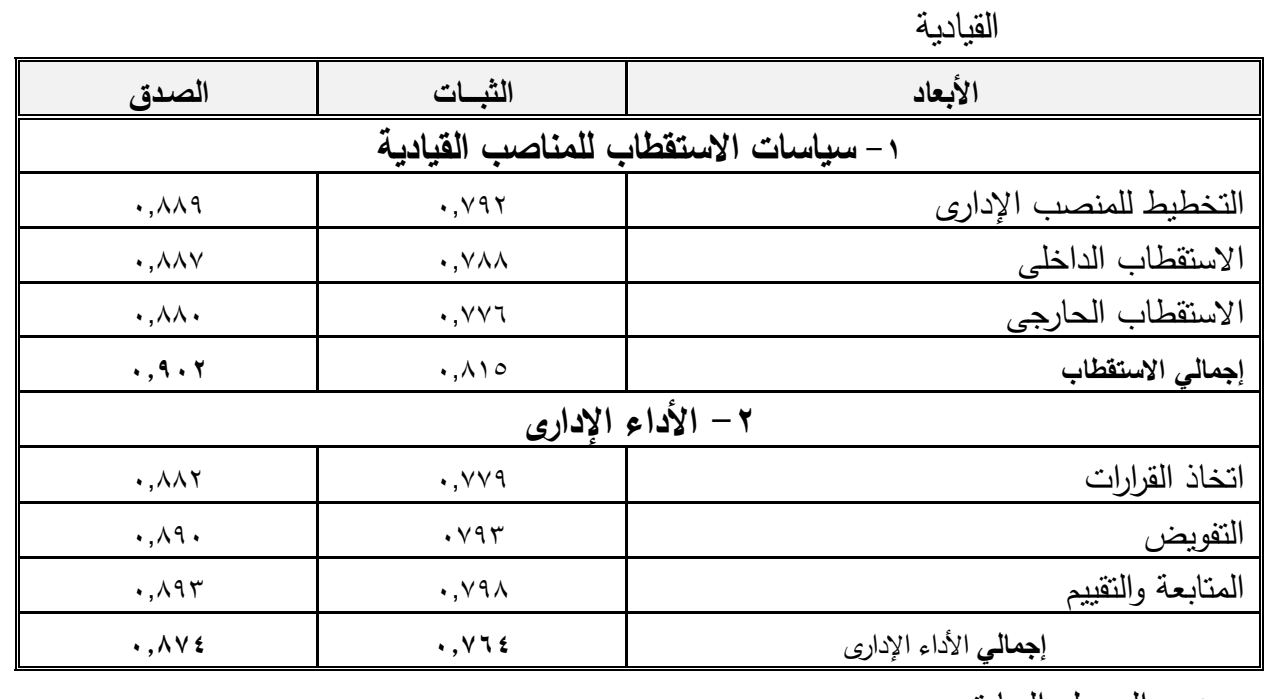

$$
\text { يوضح الجدول السابق: }
$$

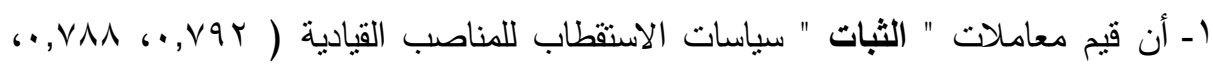

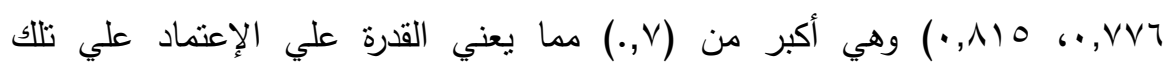
المقاييس.

r- أن قيم معاملات " الصدق " لأبعاد سياسات الاستقطاب للمناصب القيادية (

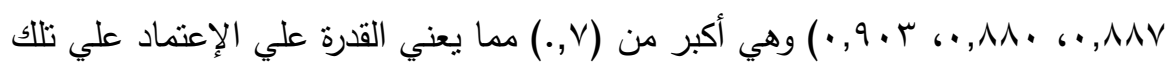

$$
\text { المقاييس. }
$$

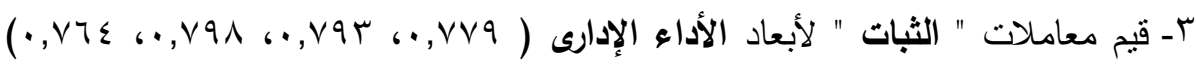

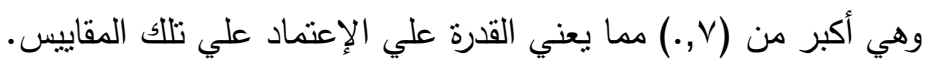

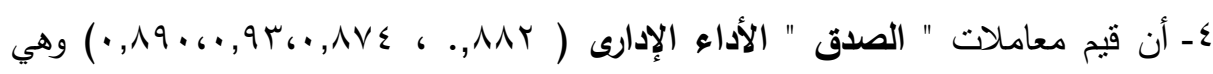

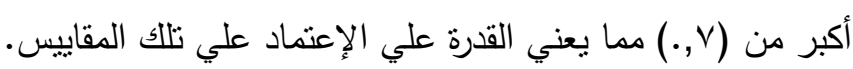

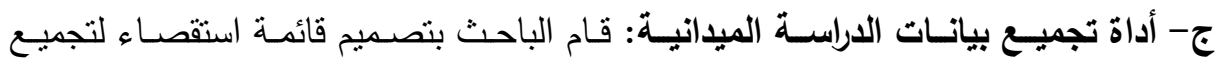
البيانات من مفردات البحث، حيث مر إعدادها وتصميمها بالخطونين التاليتين: الخطوة الأولى: إعداد قائمة الاستقصاء فى صورتها الأولية: 
وصف عينة الاراسة: تم إجراء الدراسة علي عدد . امفرده حيث تم إجراء الاستقصاء علي رؤساء القطاعات ومديري العموم بهذه الثركة نظرا لانهم هم المنوط لهم بعملية الاستقطاب

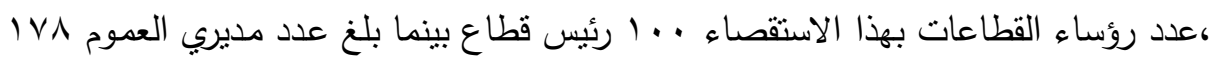
مدير عام بهذه الشركات كما هو موضح باءهاتلاتي: الخطوة الثانية: استيفاء بيانات قوائم الاستقصاء واعدادها للتحليل العصائي: قام الباحثون

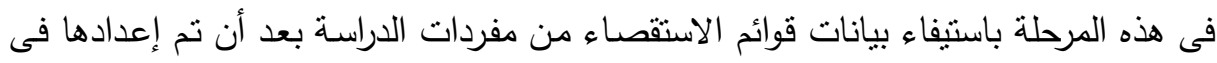

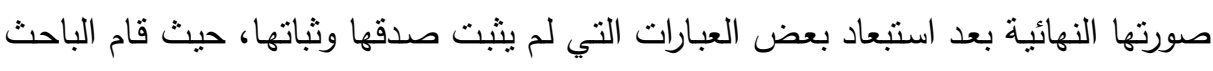
بالتوجه إلى بعض الثركات قيد الدراسـة لعرض قوائم الاستقصاء على بعض المديرين عن

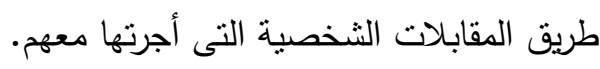
هذا كما نم مراجعة قوائم الاستقصاء بعد أن تمت الإجابة عليها، ثم قام الباحث بإدخال

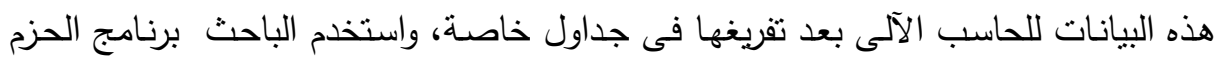

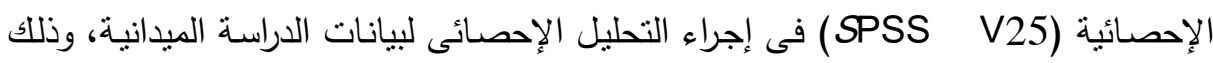
بالاستعانة بمكتب متخصص بالداسهات لإدات والتحليل الإحصائي. أساليب التحليل الإحصائي: اعتمد الباحثون على الأساليب التالية: 1- أسلوب الانحدار المتعدد: ويستخدم لحساب معاملات الانحدار المتعدد المتغير المستقل

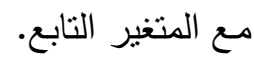
r-اختبار كروسكال ـ ولاس "Kruskal Walias Test : أحد الاختبارات اللامعلمية التي تستخدم لاختبار الفرق بين متوسطين. إن أنسب الاختبارات الإحصائية لهذا الثكل من البيانات هو اختبار كروسكال ـولاس Kruskal Walias Test" القائل بعدم وجود فروق بين الصفوف الثناتثة (عينـة الدراسـة) في استجاباتهم على أسئلة

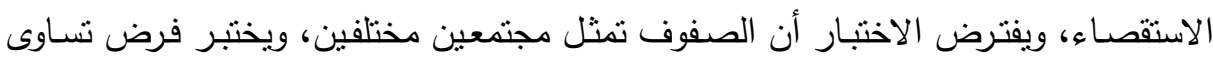

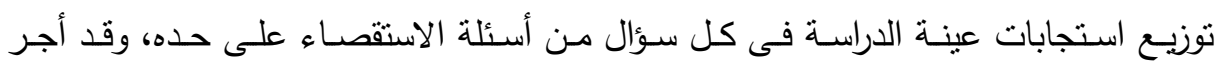


البـاحثون تحليـل البيانـات باسـتخدام اختبـار كروسـكال ــولاس لكل سـؤال مـن أسـئلة قائهــة الاستقصاء لاختبار فروض الدراسة.

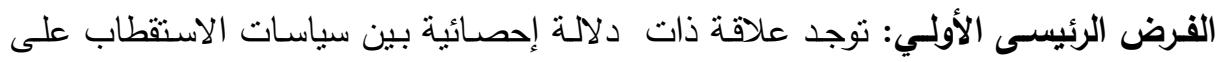
شغل المناصب الإدارية. الفرض الرئيسى الثانى: توجد علاقة ذات دلالة إحصائية بين سياسات الاستقطاب ككل على فاعلية الأداء الإدارى. الفرض الأول: توجد علاقة ذات دلالة إحصائية بين سياسات الاستقطاب على نتائج شغل المناصب الإداريه. - مان. جدول رقم (1): نقديرات نموذج الانحدار لتاثير سياسات الاستقطاب على شغل المناصب الاصب الادراية

\begin{tabular}{|c|c|c|c|c|c|}
\hline \multicolumn{4}{|c|}{ التقديرات } & \multirow{2}{*}{ F(sig.) } & \multirow{2}{*}{ معامل التحديد } \\
\hline Sig. & $t$ & $\beta$ & & & \\
\hline.,$\ldots 1$ & $\wedge, 1 \wedge 0$ & $1,1 \wedge 7$ & الثابت & \multirow{2}{*}{$\begin{array}{l}\text { YTY,OYY } \\
(\cdot,, .1)\end{array}$} & \multirow{2}{*}{$\cdot, 09 \leqslant$} \\
\hline$\cdot, \ldots$, & 9,1 & $\cdot, r 00$ & البعدالاجتماعي & & \\
\hline
\end{tabular}

المصدر: من إعداد الباحث من واقع مخرجات برنامج (SPSS V25) .

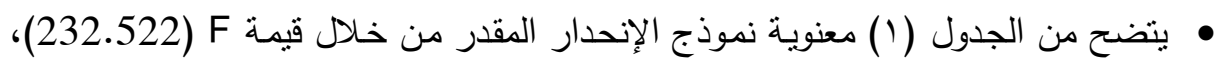

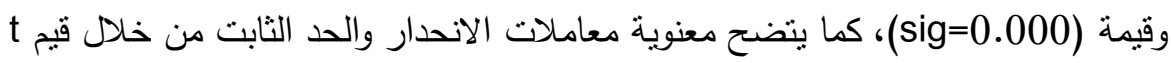

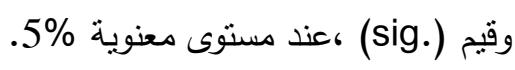

وبلغت قيمـة معامـل التحديــ (0.594) ممــ يـدل على أن المتغيـرات المستقلة تفسـر

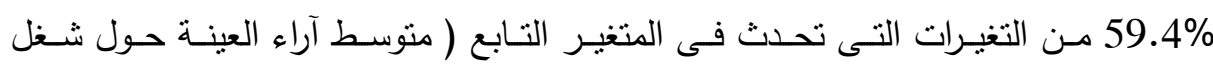
المناصب الادراية). مما سبق يتضح عدم صحة الفرض الفرعى الأول وصحة الفرض البديل:" يوجد تاثيراً معنوياً

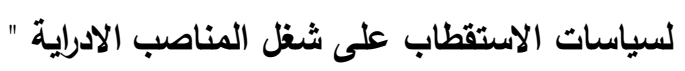


الفرض الرئيسى الثانى: لا يوجد أثر جوهري لسياسات الاستقطاب على فاعلية الأداء

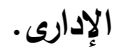
جدول رقم (ץ): تقديرات نموذج الانحدار لتاثير سياسات الاستقطاب على فاعلية الأداء

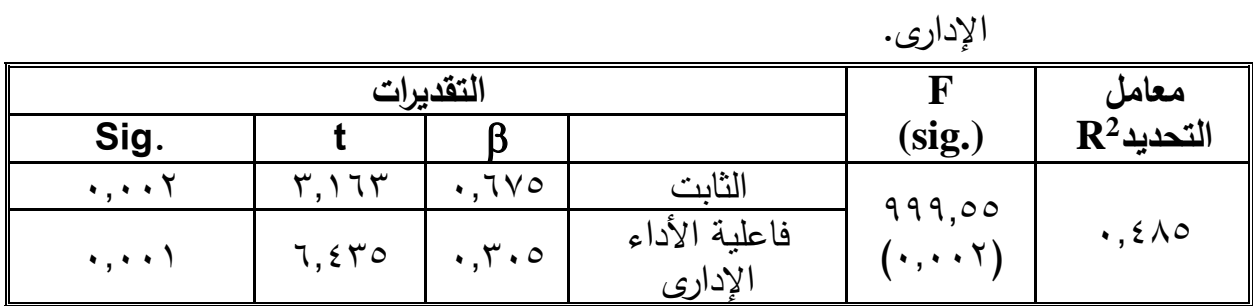

المصدر: من إعداد الباحث من واقع مخرجات برنامج (SPSS V25) .

F ويتضح من الجدول (Y) معنوية نموذج الإنحدار المقدر من خلال قيمة

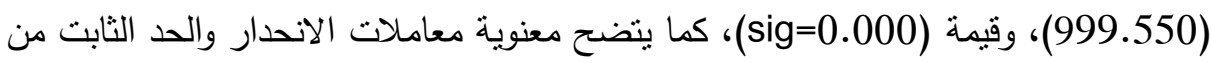

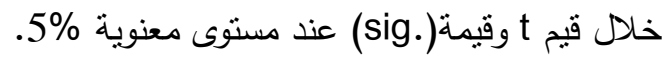

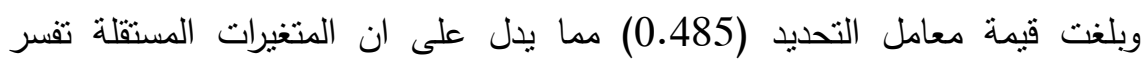
48.5\% من التغيرات التى تحدث فى المتغير التابع (متوسط آراء العينة حول فاعلية الأداء

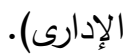

مما سبق يتضح عدم صحة الفرض الفرعى الثانى من الفرض الرئيسي وصحة الفرض البديل: " يوجد تاثيراً معنوياً لسياسات الاستقطاب على فاعلية الأداء الإدارى".

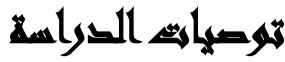

1- الاهتمام بوضع سياسات وإجراءات من شأنها ممارسة وتعزيز العمل على الاستقطاب.

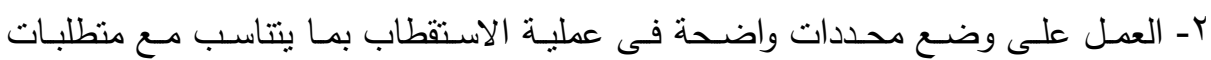

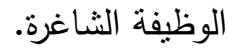


r- ضـروره إتباع سياسـة وضـع الثخص المناسب فى المكان المناسب وخصوصـاً فى دائره الاستقطاب للمناصب الإدارية. ـ- العمل على إيجاد أساليب واضحة لتطوير الوظائف القيادية من خلال دعم الثركة لجهود التطوير وتوفير كل وسائل الاتصال الفاعلة ونتويع المهارات والمعارف للقيادات العليا.

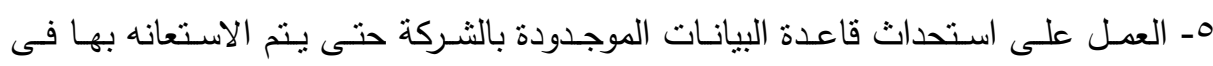
عمليات الاستقطاب للقيادات الإدارية.

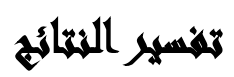

- أبدت نتائج الدراسة الباحث في التعرف على مدى انتشار سياسات الاستقطاب الموظفين

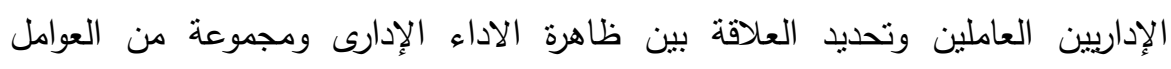

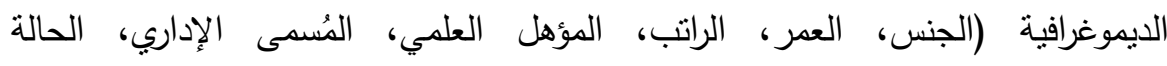
الاجتماعية) ، والكثف عن طرق الاستقطاب والسبل الكفيلة بتحفيفها.

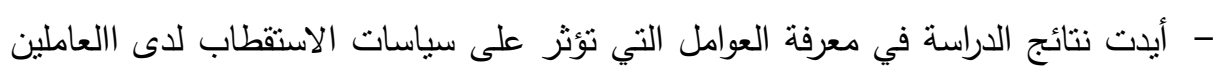
والعلاقة بين دور الاستقطاب، والعلاقة بين بيئة العمل والأاء الإدارى.

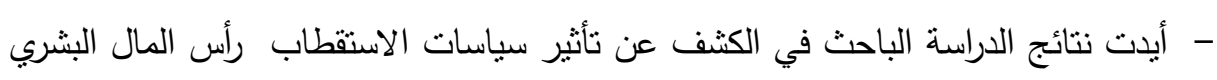
ومعرفة مدى نأثنير الإنهاك العاطفي، الثعور بالسلبية وتدني الإنجاز الثخصي على رأس المال البشري، ومعرفة أثز الابتكار والتعلم، والحافز والالتزام على رأس المال البشري. - اختلفت نتائج الدراسة في تحديد العلاقة بين سياسات الاستقطاب من ناحية، والاداء

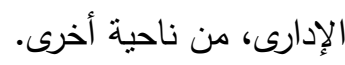

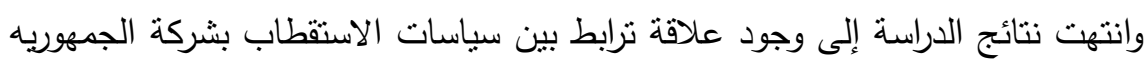
للمستلزمات الطبيه المقترحة لهذا للنطبيق. 


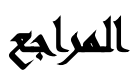

إبراهيم أحمد داوود (Y V V): "أثرالاستقطاب الإكترونى على معدل دوران الوظيفى"رسالة ماجستير، كلية الأعمال، جامعة الثرق الأوسط الألران

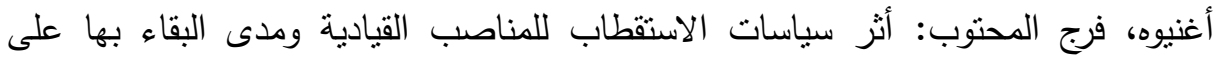

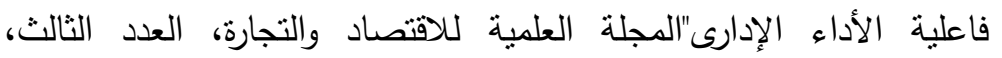

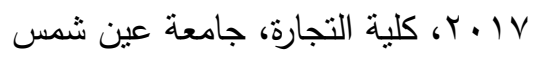

عطا، أدم حمه: "دور الاستقطاب الإكترونى فى إدارة الموارد النظريه البشرية على نجاح

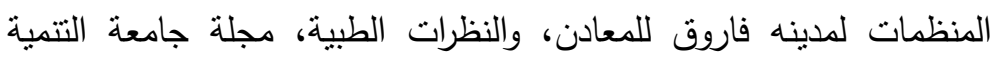

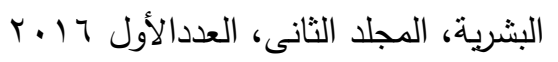

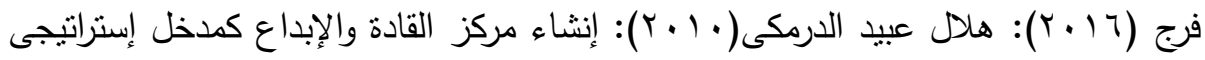

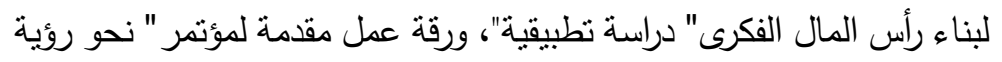

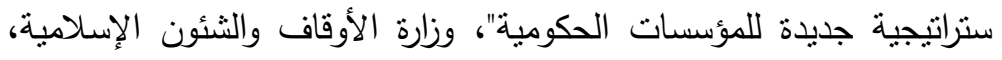

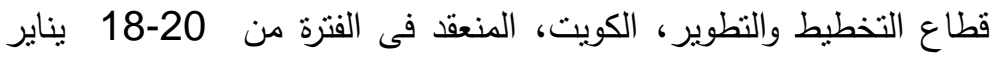

$$
r .17
$$

الكردى أحمد (• • • ( ) الإدارة المؤسسة الحديثة، علم الكتاب، القاهرة.

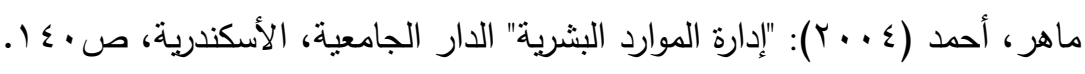

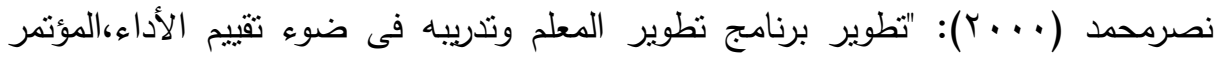

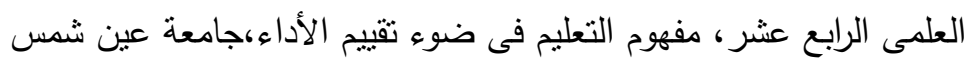

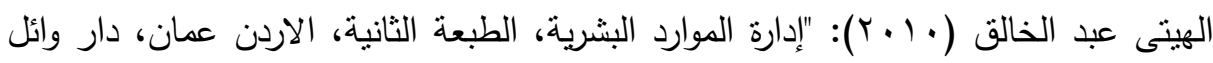
للتوزيع والنشر - لت 
Daripaly, P. (2005): 'Six Sigma : Concepts, Tools, and Applications', Industrial Management \& Data Systems, Vol. 105, No. 4, pp. 491-505

Handy. Fanlcnaan .R(2017): "The rde Of Social Anxiety in

Volunteering Non profit Management and Leadership

University if Pennsylvania vol 18.no,pp41-58

Sheila,M, and Paul K.(2017): "Betters Recruitment and Selection,

Development Desertions International Center, Washington

Pike, USA

\title{
MEASURING THE IMPACT OF POLARIZATION \\ POLICIES OF LEADERSHIP POSITIONS AND THEIR \\ IMPACT ON ADMINISTRATIVE PERFORMANCE
}

\section{A FIELD STUDY}

Mohamed A. A. Seiam

Al-Obour Higher Institute for Management, Computers, and Information Systems

\begin{abstract}
The study aims at measuring the impact of the policies of polarization for leadership positions and their impact on administrative performance and being applied to the employees of the Republic Company for Medical Supplies, through a field study to identify the adequacy, possibilities and requirements of its application to the Republic Company for Medical Supplies.
\end{abstract}

$$
\text { المجلد السابع والأربعون، الجزء الثاني، سبتمبر } 9 \text {. }
$$


In order to achieve the objectives of the study, a questionnaire form has been designed, which includes a set of statements measuring the sample's attitudes towards the variables of the study. In this study, the researcher relies on a combination of the inductive method and the deductive method, using the approach of the theoretical study and field study. The researcher has analyzed the data using the Kruskal-Wallis Test for each of the survey list questions to test the hypotheses using the study sample using the 100-items as the study sample "the number of valid forms recovered". The researcher has reached a set of results and recommendations that can be applied to under-study facility (Republic Company for Medical Supplies).

\section{The study concludes that:}

1. Considering the development and setting of policies and procedures that will practice and promote the work of polarization.

2. Working on the establishment of clear evident determinants in the process of polarization commensurate with the requirements of the vacancy.

3. The need to follow the policy of placing the right person in the right place, especially in the circle of polarization of administrative positions. 